Research Article

\title{
Experimental and Numerical Study of Texture Evolution and Anisotropic Plastic Deformation of Pure Magnesium under Various Strain Paths
}

\author{
Hamad F. Alharbi $(\mathbb{D}$, Monis Luqman, Ehab El-Danaf $(\mathbb{D}$, and Nabeel H. Alharthi \\ Mechanical Engineering Department, College of Engineering, King Saud University, P.O. Box 800, 11421 Riyadh, Saudi Arabia \\ Correspondence should be addressed to Hamad F. Alharbi; harbihf@ksu.edu.sa
}

Received 1 September 2017; Accepted 23 November 2017; Published 30 January 2018

Academic Editor: Ivan Gutierrez-Urrutia

Copyright (c) 2018 Hamad F. Alharbi et al. This is an open access article distributed under the Creative Commons Attribution License, which permits unrestricted use, distribution, and reproduction in any medium, provided the original work is properly cited.

\begin{abstract}
The deformation behavior and texture evolution of pure magnesium were investigated during plane strain compression, simple compression, and uniaxial tension at room temperature. The distinctive stages in the measured anisotropic stress-strain responses and numerically computed strain-hardening rates were correlated with texture and deformation mechanisms. More specifically, in plane strain compression and simple compression, the onset of tensile twins and the accompanying texture-hardening effect were associated with the initial high strain-hardening rates observed in specimens loaded in directions perpendicular to the crystallographic $c$-axis in most of the grains. The subsequent drop in strain-hardening rates in these samples was correlated with the exhaustion of tensile twins and the activation of pyramidal $<\mathrm{c}+\mathrm{a}\rangle$ slip systems. The falling strain-hardening rates were observed in simple compression and plane strain compression with loading directions parallel to the $c$-axis where the second pyramidal $<\mathrm{c}+\mathrm{a}>$ slip systems were the only slip families that can accommodate deformation. For uniaxial tension with the basal plane parallel to the tensile axis, the prismatic $<a>$ and second pyramidal $<\mathrm{c}+\mathrm{a}>$ slips are the main deformation mechanisms. The predicted relative slip and twin activities from the crystal plasticity simulations clearly showed the effect of texture on the type of activated deformation mechanisms.
\end{abstract}

\section{Introduction}

Magnesium and its alloys have potential applications in automobile and aerospace industries due to their low density, high specific strength, and good castability $[1,2]$. However, magnesium materials have low ductility at room temperature compared to other ductile metals $[3,4]$. The low ductility in magnesium can be generally attributed to the lack of independent easy-activated slip systems that can accommodate large plastic strains.

Magnesium has a close-packed (hcp) crystal structure and exhibits a high degree of plastic anisotropy due to the possible activation of various slip and twin families and the resulting pronounced texture. The slip systems include the basal $<\mathrm{a}\rangle$, prism $<$ a $>$, pyramidal $<$ a $>$, and second pyramidal $<\mathrm{c}+\mathrm{a}\rangle$ slip systems [5-7]. The basal $<a>$ family is the easiest slip system to activate in magnesium with lower slip resistance compared to the other systems. The second pyramidal $\langle\mathrm{c}+\mathrm{a}\rangle$ slip system is the only slip family that can accommodate plastic strain in the basal normal direction (all the other slip systems operate in the basal $<$ a $>$ direction only), but it is also very hard to activate. Twinning is an alternative deformation mechanism in magnesium that can also accommodate plastic strains in the nonbasal directions. The $\{10 \overline{1} 2\}<\overline{1} 011>$ tensile twins and the $\{10 \overline{1} 1\}<10 \overline{12}>$ contraction twins are the most common twin systems observed in magnesium and its alloys [8-11]. The extension twins give extension along the crystallographic $c$-axis in magnesium and reorient the crystal by $86^{\circ}$ around $<1 \overline{2} 10>$ directions, while the contraction twins supply contraction along the crystallographic $c$-axis and reorient the crystal by $56^{\circ}$ around $<1 \overline{2} 10>$ directions $[8,9]$.

The extension twins are readily observed in magnesium and its alloys during simple compression tests when the loading direction is perpendicular to the crystallographic 
$c$-axis of the crystal. Such deformation modes are commonly triggered in textured (polycrystalline) magnesium when compressed parallel to the extrusion direction of an extruded bar or compressed perpendicular to the normal direction of a rolled sheet [10-12]. The extension twins can also be activated in magnesium during a uniaxial tension if the tensile loading direction is parallel to the crystallographic $c$-axis of the lattice crystals $[13,14]$. The activation of extension twins in magnesium has important implications on the texture evolution and strain-hardening rates. The initial high strainhardening rates observed in magnesium are commonly linked to the activation of extension twins in the early stage of deformation. The widely accepted hypothesis for the physical mechanism by which deformation twinning contributes to the unusually high strain-hardening rates is the texture hardening, where tensile twins usually reorient the grains into hard (unfavored slip) orientations. An alternative hypothesis for explaining the high strain-hardening rates associated with the onset of deformation twinning is the Hall-Petch-like effect, where twinning divides the grains thereby reducing the effective slip distance [15-18]. However, the latter explanation is not likely to be effective due to the fast growth (thickening) of tensile twins in magnesium until it consumes the entire grain.

The current study presents detailed investigations of the mechanisms that govern the anisotropic plastic response of pure magnesium under various strain paths at room temperature. We have measured the anisotropic stress-strain response in different mechanical tests including plane strain compression, simple compression, and uniaxial tensile tests in different sample directions that were initially processed by extrusion and rolling. We have also measured the texture of the initial and deformed samples using electron backscattered diffraction (EBSD) technique. The differences in the strain-hardening responses and texture evolution between uniaxial loading and plane strain compression tests under certain loading directions were discussed. The highly observed plastic anisotropy in pure $\mathrm{Mg}$ was related to the type of predominant slip and/or twin deformation modes in each sample orientation and supported by predictions from crystal plasticity simulation. Such information is important for developing more accurate crystal plasticity models for Mg alloys.

\section{Experimental Procedure}

The material used in this study was an as-cast billet of highpurity magnesium (99.9\%). A cylindrical bar with $35 \mathrm{~mm}$ (diameter) $\times 50 \mathrm{~mm}$ (long) and a plate of $70 \mathrm{~mm} \times 58 \mathrm{~mm} \times$ $19 \mathrm{~mm}$ were cut from the billet for extrusion and rolling processing, respectively. The cylindrical bar and plate were first annealed at $250^{\circ} \mathrm{C}$ in a vacuum tube furnace for $4 \mathrm{hrs}$. The cylindrical bar was then hot extruded at $250^{\circ} \mathrm{C}$ from $35 \mathrm{~mm}$ to $15 \mathrm{~mm}$ ( $\sim 5.4$ extrusion ratio), and the plate was hot rolled at about $200^{\circ} \mathrm{C}$ from $19 \mathrm{~mm}$ to $8.6 \mathrm{~mm}(\sim 55 \%$ reduction in thickness) in multiple passes. The extruded bar and rolled plate were subsequently used to fabricate five sets of samples with different orientations to investigate the effect of strain path change and the associated texture on the anisotropic mechanical response of pure magnesium under various mechanical tests.

Five sets of samples with different orientations were machined from the cylindrical extruded bar and rolled plate for subsequent mechanical tests as depicted in Figure 1. The orientations of the five set of samples were designed such that the loading directions in the mechanical tests align either perpendicular or parallel to the typical crystallographic orientations of the $c$-axis resulting from extrusion and rolling processes. These samples were subjected to plane strain compression (PSC) $\left(\mathrm{ND}_{0} \mathrm{ED}_{0}\right.$ and $\mathrm{ND}_{0} \mathrm{ED}_{0}$ samples), simple compression $\left(\mathrm{CA} 0 \mathrm{ED}_{0}\right.$ and $\mathrm{CA} 0 \mathrm{ND}_{0}$ samples), and uniaxial tensile (TA90ND $\mathrm{N}_{0}$ sample) tests at room temperature. The orientations of these samples can be distinguished by their labels, where the number in the label illustrates the angle between the loading direction in the mechanical test and the original processing direction (extrusion direction $\mathrm{ED}_{0}$ of the extruded bar or normal direction $\mathrm{ND}_{0}$ of the rolled plate). As an example, the label of $\mathrm{ND} 90 \mathrm{ED}_{0}$ sample indicates that the loading (normal) direction ND in the PSC test makes an angle of $90^{\circ}$ with respect to the original extrusion direction $\mathrm{ED}_{0}$. The labels also show the rolling (RD), transverse (TD), and normal (ND) directions in plane strain compression, compression axis (CA) in simple compression, and tensile axis (TA) in uniaxial tensile tests. Two specimens for each set of orientations were mechanically tested, and the variance in the measured stressstrain responses between the two samples tested for each group was found to be very small.

The plane strain compression (PSC) tests were carried out in a channel die that allows an elongation of the specimens in $\mathrm{RD}$ direction only, whereas deformation is suppressed in TD direction. Teflon sheet and high-pressure grease were used between the sample and the die surfaces to reduce frictional effect. The dimensions of the specimens for the PSC tests were $11 \mathrm{~mm}(\mathrm{RD}) \times 8 \mathrm{~mm}(\mathrm{TD}) \times 7 \mathrm{~mm}(\mathrm{ND})$. As the labels of the PSC specimens indicate, the loading direction ND is perpendicular to the original extrusion direction $\mathrm{ED}_{0}$ in $\mathrm{ND} 0 \mathrm{ED}_{0}$ samples, whereas it is parallel to $\mathrm{ED}_{0}$ in $\mathrm{ND} \mathrm{ED}_{0}$ samples. For simple compression test, cylindrical samples were cut with dimensions of $13 \mathrm{~mm}$ (diameter) $\times 20 \mathrm{~mm}$ (height) and $5 \mathrm{~mm}$ (diameter) $\times 8 \mathrm{~mm}$ (height) for $\mathrm{CAOED}_{0}$ and $\mathrm{CA} 0 \mathrm{ND}_{0}$, respectively. The $\mathrm{CA} 0 \mathrm{ED}_{0}$ samples were machined from the cylindrical extruded bar with the compression axis CA parallel to $\mathrm{ED}_{0}$, while $\mathrm{CA} 0 \mathrm{ND}_{0}$ samples were cut from the rolled plate with CA parallel to the plate's normal direction $\mathrm{ND}_{0}$. The tensile specimens $\mathrm{TA} 90 \mathrm{ND}_{0}$ were machined from the rolled plate in the $\mathrm{TD}_{0}-\mathrm{RD}_{0}$ plane with the tensile axis $\mathrm{TA}$ parallel to the plate's rolling direction $\mathrm{RD}_{0}$. The tensile samples were machined as per ASTM E8 with a gauge length of $25 \mathrm{~mm}$. All mechanical tests were performed at room temperature with a constant initial strain rate of about $10^{-3} \mathrm{~s}^{-1}$, using a screwdriven INSTRON machine. The raw data of the PSC and simple compression tests were corrected for machine compliance. The change of gauge length in the uniaxial tensile tests was measured using an axial extensometer (Epsilon 35420125M).

The texture and microstructure evolutions of all samples were characterized using a field-emission scanning electron microscope (JEOL JSM-7600F) equipped with an electron 


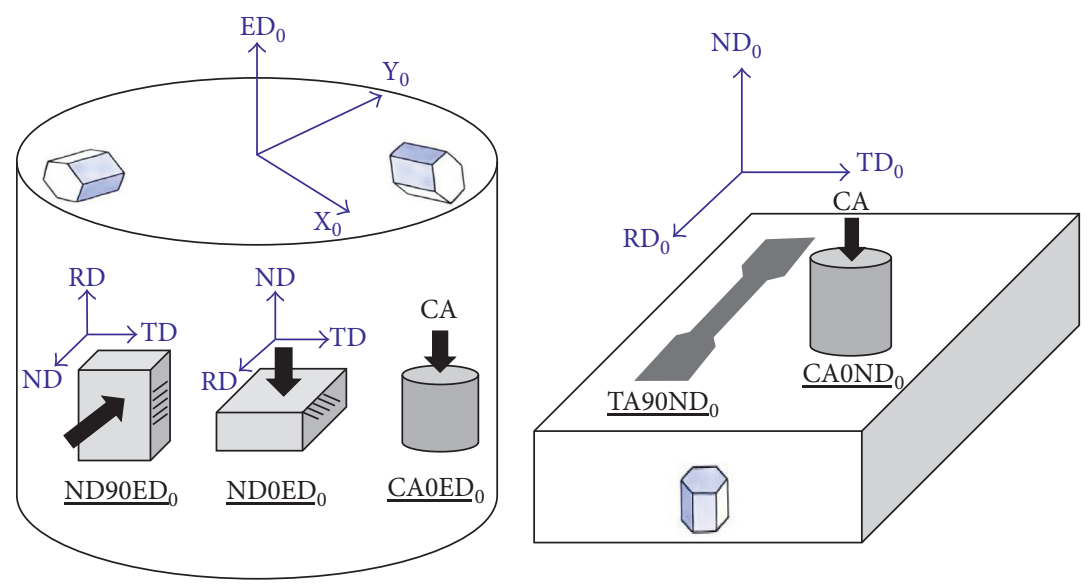

Figure 1: Schematic illustration of the orientations of the samples machined from the cylindrical extruded bar and rolled plate and used in

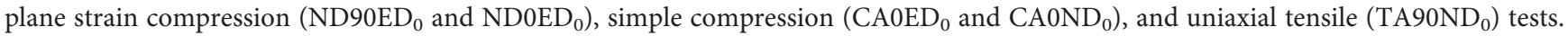
The typical crystallographic orientations of the $c$-axis resulting from extrusion and rolling processes are also shown.

backscattered diffraction (EBSD) camera supplied by Oxford Instruments. The specimens were prepared for EBSD scanning by mechanical polishing using subsequent oilbased diamond suspensions of 9,3 , and $1 \mu \mathrm{m}$, respectively. This was followed by $4-6 \mathrm{~s}$ chemical etching using a solution of $60 \mathrm{ml}$ ethanol, $20 \mathrm{ml}$ distilled water, $15 \mathrm{ml}$ acetic acid, and $5 \mathrm{ml}$ nitric acid. The EBSD scan areas for all samples were taken as large as possible $(>700 \mu \mathrm{m} \times 700 \mu \mathrm{m})$ to provide a more representative texture information, but with a slightly large step size of $1 \mu \mathrm{m}$ to be able to complete the scanning in a reasonable time.

\section{Experimental Results}

3.1. True Stress-Strain Curves and Strain-Hardening Rates. The true stress-strain curves measured on different pure magnesium samples under various mechanical tests including PSC, simple compression, and uniaxial tensile are shown in Figure 2. In order to easily compare the mechanical responses between the different tests, the flow curves are plotted based on the von Mises definition of the equivalent stress and equivalent strain [19]. The strong anisotropic plastic deformation responses shown in Figure 2 have been reported in prior literature for magnesium and its alloys (e.g. [11, 13, 14, 20, 21]). Figure 3 shows the corresponding strain-hardening rates computed numerically from the stress-strain curves. The strain-hardening rates were normalized by the shear modulus of magnesium. This figure clearly indicates the major differences in the strainhardening behavior between the different specimens tested in this study.

3.2. Microstructure and Texture Evolution. Microstructure and texture evolutions of all specimens were investigated by EBSD scanning which reveals both the structure and crystallographic orientations of the grains. Figure 4 shows the EBSD inverse pole figure (IPF) maps and pole figures of the cylindrical extruded bar and rolled plate that were used to fabricate all five sets of samples shown in Figure 1. The

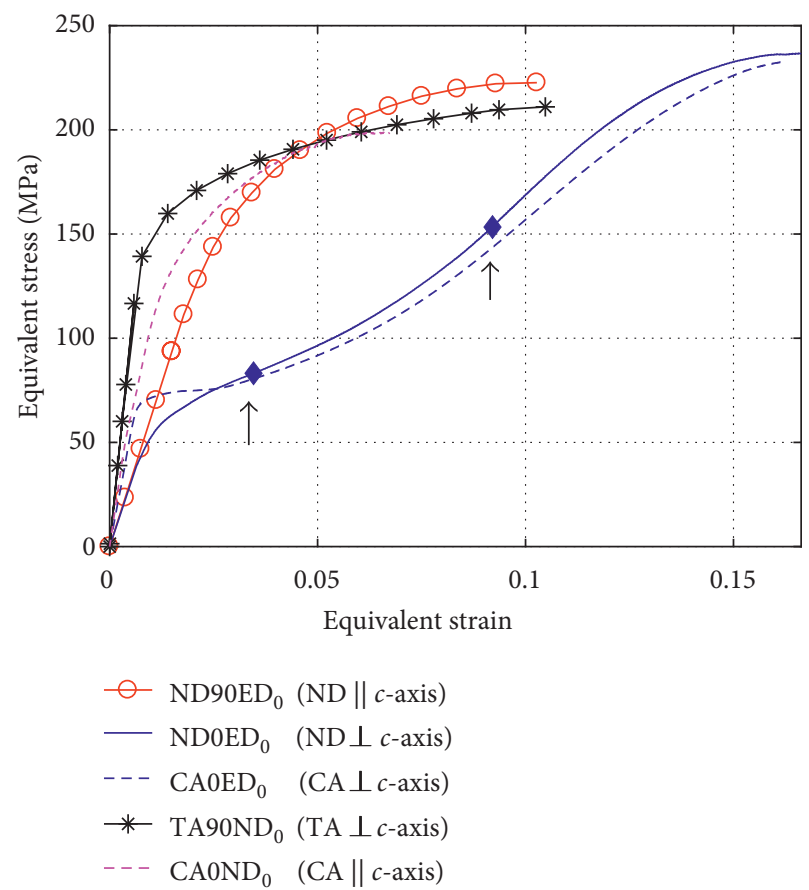

FIgURE 2: Flow curves of pure magnesium at room temperature under different mechanical tests including PSC $\left(\mathrm{ND}_{0} \mathrm{ED}_{0}\right.$ and $\left.\mathrm{ND}_{0 \mathrm{ED}}\right)$, simple compression $\left(\mathrm{CA} 0 \mathrm{ED}_{0}\right.$ and $\left.\mathrm{CA} 0 \mathrm{ND}_{0}\right)$, and uniaxial tensile $\left(\mathrm{TA} 90 \mathrm{ND}_{0}\right)$. The loading directions with respect to the typical crystallographic $c$-axis in most grains for each specimen are shown between parentheses.

IPF maps are collected on planes perpendicular to the extrusion direction $\left(\mathrm{ED}_{0}\right)$ and normal direction $\left(\mathrm{ND}_{0}\right)$ of the cylindrical extruded bar and rolled plate, respectively. Therefore, the IPF maps reflect the orientations of the extruded bar's extrusion direction $\left(\mathrm{ED}_{0}\right)$ and rolled plate's normal direction $\left(\mathrm{ND}_{0}\right)$ with respect to the local crystal frames. The measured pole figures clearly indicate that the extruded bar exhibited a typical prismatic $10 \overline{1} 0$ fiber texture, where basal planes oriented parallel to the extrusion 

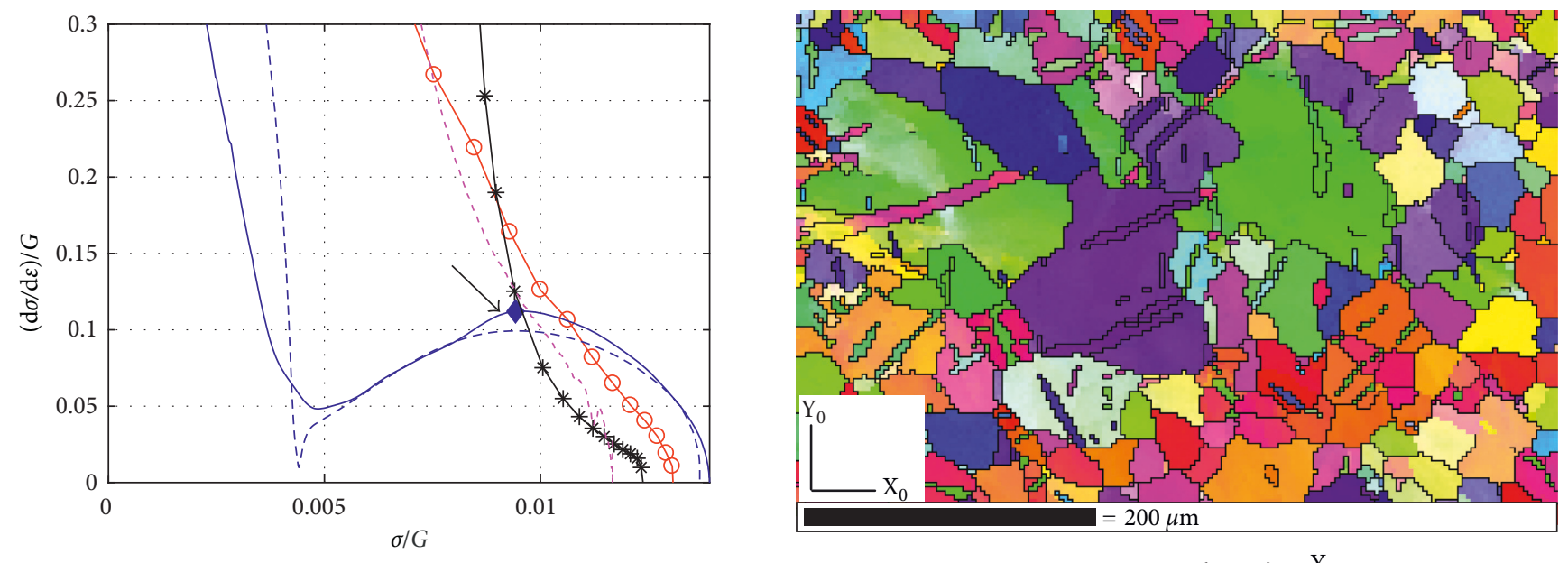

$$
\begin{aligned}
& \text { - } \mathrm{ND}^{-0 E D_{0}}(\mathrm{ND} \| c \text {-axis }) \\
& \text { — ND90ED } 0_{0} \text {-old (ND } \| c \text {-axis) } \\
& \text { - - } \mathrm{ND}^{-E_{0}} \quad(\mathrm{ND} \perp c \text {-axis) } \\
& \text { * } \mathrm{CA} \mathrm{ED}_{0} \quad(\mathrm{CA} \perp c \text {-axis }) \\
& \text { - - } \mathrm{TA}^{20 \mathrm{ND}_{0}}(\mathrm{TA} \perp c \text {-axis) }
\end{aligned}
$$

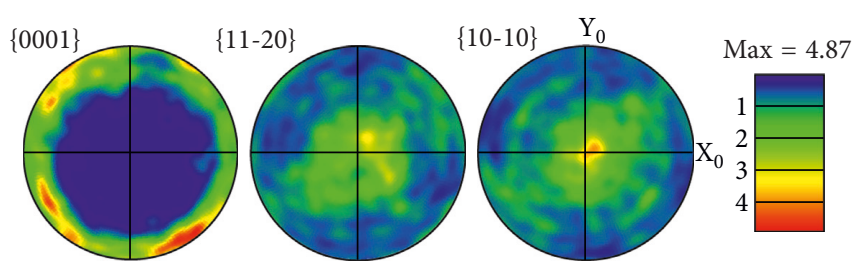

FIGURE 3: Normalized strain-hardening responses of pure magnesium at room temperature under different mechanical tests including PSC $\left(\mathrm{ND}_{0} \mathrm{ED}_{0}\right.$ and $\left.\mathrm{ND}_{0} \mathrm{ED}_{0}\right)$, simple compression $\left(\mathrm{CA} 0 \mathrm{ED}_{0}\right.$ and $\left.\mathrm{CA} 0 \mathrm{ND}_{0}\right)$, and uniaxial tensile $\left(\mathrm{TA} 90 \mathrm{ND}_{0}\right)$.

direction $\mathrm{ED}_{0}$ (or the crystallographic $c$-axis in most grains oriented in a radial direction that is perpendicular to $\mathrm{ED}_{0}$ ) (e.g. [22-27]). The rolled plate also showed a typical fiber texture with the crystallographic $c$-axis in most grains aligned parallel to plate's normal direction $\mathrm{ND}_{0}$ (e.g. [21, 28, 29]). Based on this texture, the orientations of the five sets of samples were designed such that the loading directions in the mechanical tests align either perpendicular or parallel to the typical crystallographic $c$-axis in most of the grains. More specifically, the loading direction was selected to be (1) parallel to the crystallographic $c$-axis in most grains in the samples $\mathrm{ND} 90 \mathrm{ED}_{0}$ and $\mathrm{CAOND}_{0}$ and (2) perpendicular to the crystallographic $c$-axis in most grains in the samples $\mathrm{ND} \mathrm{ED}_{0}$, $\mathrm{CA} 0 \mathrm{ED}_{0}$, and $\mathrm{TA} 90 \mathrm{ND}_{0}$. In order to make this clear, we show in Figure 5 the $\{0001\}$ and $\{10 \overline{1} 0\}$ pole figures of the initial texture for all samples using the new reference frame for each mechanical test which were obtained by appropriate rotations of the pole figures in Figure 4.

The texture and microstructure of all specimens after each mechanical test are collected by EBSD scanning. For the purpose of simplicity and clarity, the texture will be described in terms of the orientation of the crystallographic $c$-axis in the crystal with respect to the loading direction in the mechanical test. The texture of $\mathrm{ND} 0 \mathrm{ED}_{0}$ and $\mathrm{ND} 0 \mathrm{ED}_{0}$ samples after PSC tests at room temperature is shown in Figure 6. The EBSD scans were acquired in the RD-TD plane in the midsection of the sample. It is clear that the crystallographic $c$-axis in most grains aligns parallel to ND direction in both $\mathrm{ND} 9 \mathrm{ED}_{0}$ and $\mathrm{ND} \mathrm{ED}_{0}$ samples after PSC tests (the poles reappear at the center of the pole figures for both samples). It should be noted that even though the

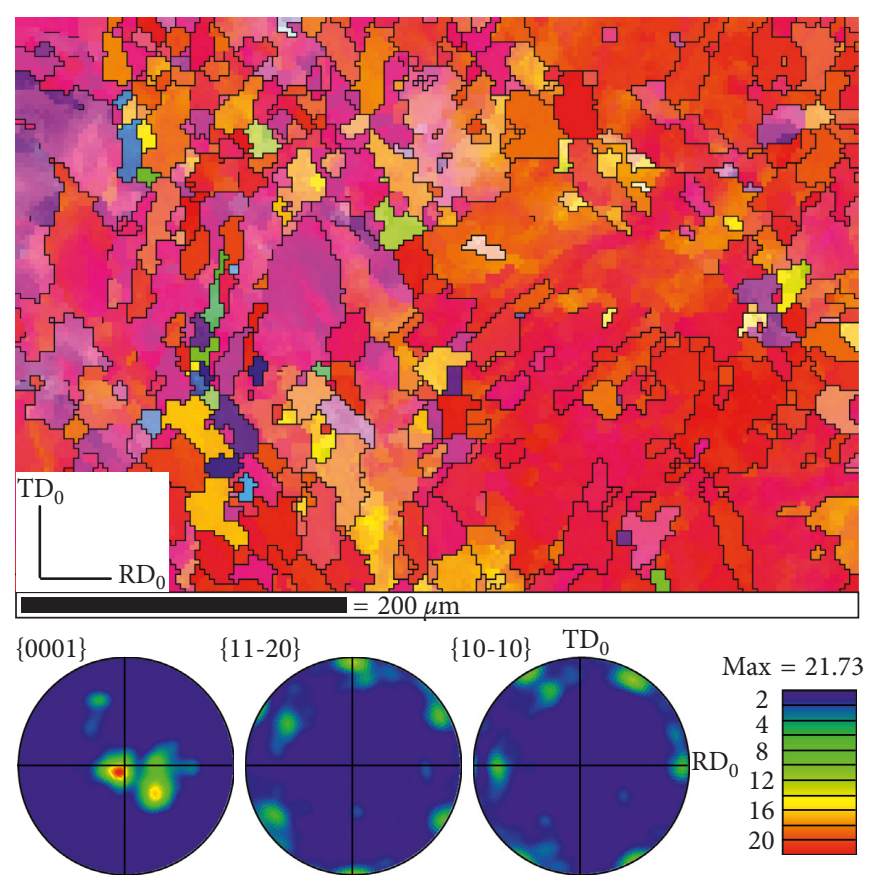

(b)

FIgURE 4: EBSD inverse pole figure (IPF) maps (top) and pole figures (bottom) showing microstructure and texture of the (a) cylindrical extruded bar and (b) rolled plate of the pure magnesium. The IPF maps reflect the orientations of the bar's extrusion direction $\left(\mathrm{ED}_{0}\right)$ and rolled plate's normal direction $\left(\mathrm{ND}_{0}\right)$ with respect to the local crystal frames. The measured pole figures show the initial texture of the processed (extruded and rolled) material. The reference frames $\left(\mathrm{X}_{0}, \mathrm{Y}_{0}, \mathrm{ED}_{0}\right)$ and $\left(\mathrm{RD}_{0}, \mathrm{TD}_{0}, \mathrm{ND}_{0}\right)$ are the same as in Figure 1.

starting texture for $\mathrm{ND} 90 \mathrm{ED}_{0}$ and $\mathrm{ND0ED} \mathrm{D}_{0}$ samples was different (Figures 5(a) and 5(b)), the final texture after PSC tests for the two set of samples was found to be similar. The 


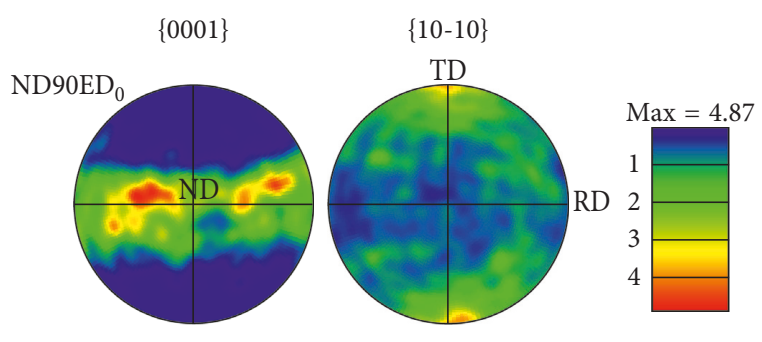

(a)

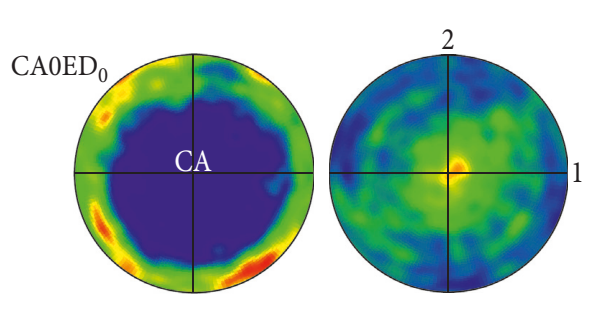

(c)
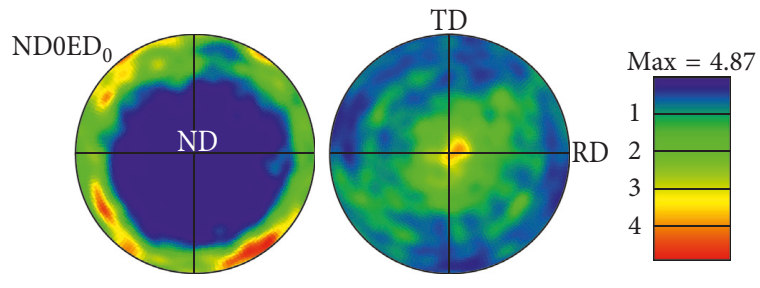

(b)
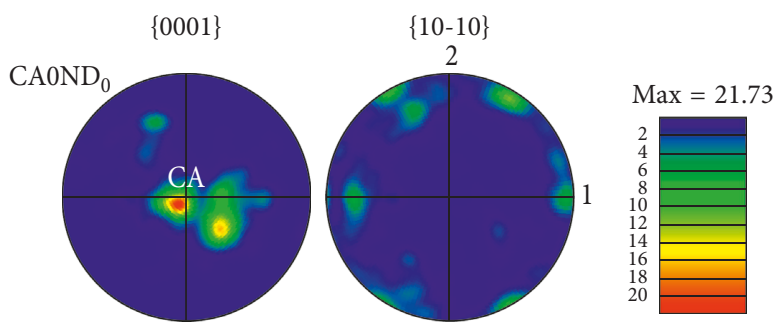

(d)
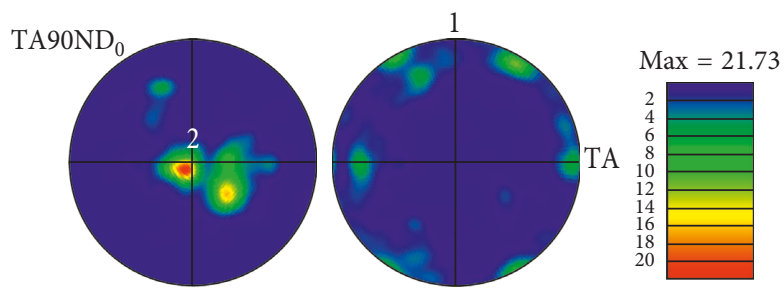

(e)

FIGURE 5: $\{0001\}$ and $\{10 \overline{1} 0\}$ pole figures of the initial texture for the five set of samples shown in Figure 1 using the reference frame for each mechanical test: (RD, TD, ND) for PSC, $(1,2, \mathrm{CA})$ for simple compression and (1, 2, TA) for uniaxial tension, where 1 and 2 refer to the lateral directions of the compression or tension test. The pole figures were obtained by appropriate rotations of the pole figures shown in Figure 4 with respect to the new reference frame. (a) $\mathrm{ND}_{00 \mathrm{ED}}$. (b) $\mathrm{ND}_{0} \mathrm{ED}_{0}$. (c) CA0ED . (d) $\mathrm{CAOND}_{0}$. (e) $\mathrm{TA}_{90 \mathrm{ND}}$.

reason for such texture change is related to the type of deformation mechanisms, which will be explained in more detail in Discussion. Figures $7(\mathrm{a})$ and $7(\mathrm{~b})$ present the texture after simple compression test at room temperature for $\mathrm{CAOED}$ and $\mathrm{CAOND}$ samples, respectively. The pole figures are collected in a plane normal to the compression axis CA in the midsection of the sample, with CA lying at the center of the pole figures. It is seen once again that even though the starting texture for $\mathrm{CA0ED}$ and $\mathrm{CA} 0 \mathrm{ND}_{0}$ samples is different (Figures 5(c) and 5(d)), the final texture after simple compression test is similar to the crystallographic $c$-axis in most grains that align parallel to the loading direction CA in both $\mathrm{CA} 0 \mathrm{ED}_{0}$ and $\mathrm{CA}_{0} \mathrm{ND}_{0}$ samples. Lastly, the texture after uniaxial tensile test for the TA90ND sample is illustrated in Figure 7(c) which is collected in the tensile plane about $3 \mathrm{~mm}$ apart from the fracture surface in the gauge length region. It is noted that the texture of TA90ND ${ }_{0}$ sample after the tensile test has little change compared to the initial texture.

\section{Discussions}

4.1. Deformation Mechanisms and Texture Evolution. The deformation behavior of magnesium and its alloys can be very different depending on the initial texture and the type of plastic deformation mechanisms. The mechanical deformation behavior of the pure magnesium tested in this study as described by the flow curves shown in Figure 2 can be divided into two groups each having a special characteristic in common. The first group $\left(\mathrm{NDOED}_{0}\right.$ and $\mathrm{CAOED}_{0}$ samples) has a concave stress-strain curve consisting of an initial drop in hardening rate followed by a marked increase up to a true strain of 0.1 where another drop is noticed. On

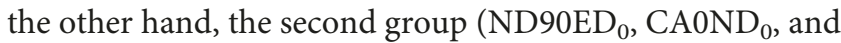
TA90ND $\mathrm{Namples}_{0}$ has the typical falling strain-hardening rates similar to the saturation-type hardening observed in high and medium staking fault energy face-centered cubic metals. The offset yield point for the samples in the first group is about $75 \mathrm{MPa}$, whereas it is about $130 \mathrm{MPa}$ for the samples in the second group. All flow curves in both groups have a sharp loss of strength at the end of the mechanical tests accompanied by the occurrence of inhomogeneous deformation in terms of shear cracks. It should be clear that this classification does not assume the same deformation mechanisms for all samples within the same group. The deformation mechanisms and texture evolution for the samples in each group are discussed next. 

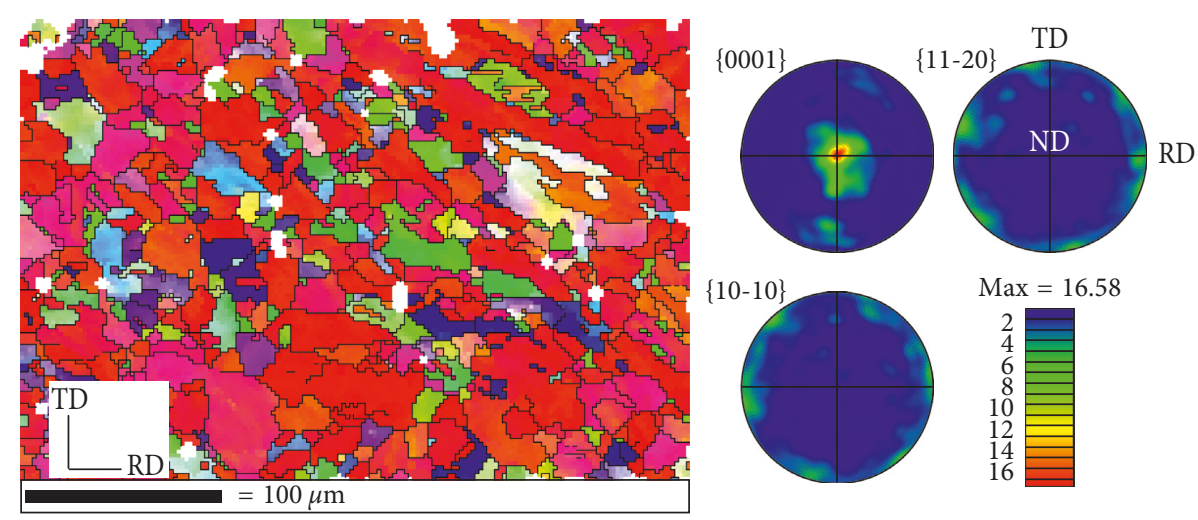

(a)
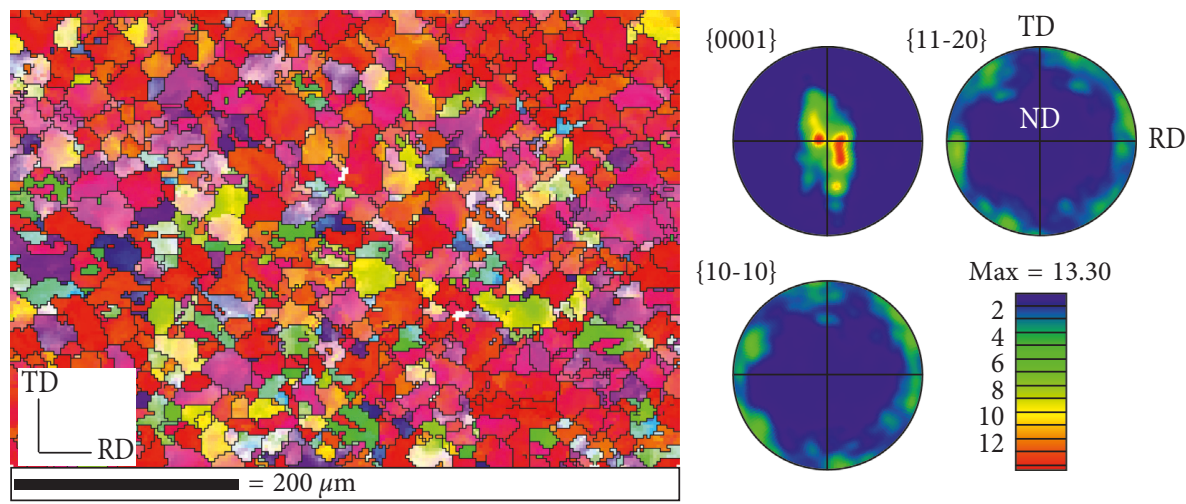

(b)

FIGURE 6: EBSD inverse pole figure (IPF) maps (left) and pole figures (right) showing microstructure and texture in RD-TD plane of the (a) $\mathrm{ND}_{\mathrm{EED}}$ and (b) $\mathrm{ND}_{0} \mathrm{ED} \mathrm{D}_{0}$ pure magnesium samples after plane strain compression. The color legend is the same as in Figure 4 .

For the first group consisting of $\mathrm{ND}_{0} \mathrm{ED}_{0}$ and $\mathrm{CAOED}_{0}$ samples, the loading (compression) direction in the mechanical tests (PSC for $\mathrm{ND} \mathrm{ED}_{0}$ and simple compression for $\mathrm{CA} 0 \mathrm{ED}_{0}$ ) aligns nearly perpendicular to the crystallographic $c$-axis in most of the grains as the texture indicated in Figures 5(b) and 5(c). This type of deformation mode is known to activate the $\{10 \overline{1} 2\}<\overline{1} 011>$ tensile twins extensively at the early stage of deformation $[21,30]$. This twin mode reorients the crystal by $86^{\circ}$ around $<1 \overline{2} 10>$ directions bringing the basal plane to be nearly perpendicular to the loading direction. The formation of this basal texture ( $\{0001\}$-fiber texture) leads to texture hardening where most grains become hard to deform with the $c$-axis nearly parallel to the loading axis. The $\{10 \overline{1} 2\}$ tensile twinning in our samples appears to start at an axial true strain of about 0.03 in $\mathrm{ND}_{0 \mathrm{ED}}$ and $\mathrm{CAOED}_{0}$ samples. This strain value corresponds to the points at which the strain-hardening rates start to increase as illustrated in Figures 2 and 3 (marked using arrows, note that Figure 2 shows the equivalent strain). This observation is in agreement with previously reported experiments in $\mathrm{Mg}$ alloys that detected the initial appearance of tensile twins at strains in the range of 0.02 to $0.04[21,31]$. It should be clear that, in this study, we have not tried to detect the initial appearance of tensile twins experimentally at this small-strain level since this would require interrupting the mechanical tests frequently. The production of extension twins and the accompanied texture hardening lead to the sharp increase in flow stresses only after a small amount of true strain, where the flow stresses increased from about $80 \mathrm{MPa}$ to about $160 \mathrm{MPa}$ by a true strain of about 0.07 in both $\mathrm{ND}_{0} \mathrm{ED}_{0}$ and $\mathrm{CA} 0 \mathrm{ED}_{0}$ samples. Therefore, the very high strain-hardening rates observed in samples $\mathrm{ND}_{0 \mathrm{ED}}$ and $\mathrm{CA0ED}$ can be attributed to the activation of extension twins and the associated texturehardening effect. Furthermore, the exhaustion of extension twins in these samples is estimated to occur at about 0.08 strain. This strain value corresponds to the peak strainhardening rates shown in Figure 3. It should be noted that this value is very close to the maximum shear strain that can be produced by extension twins, estimated to be 0.1289 shear strain (or about 0.065 axial strain). In other words, most of the grains in $\mathrm{ND} \mathrm{ED}_{0}$ and $\mathrm{CA} 0 \mathrm{ED}_{0}$ samples are expected to form a basal texture due to extension twins at about 0.08 strain. The plastic strain after the exhaustion of extension twins beyond an equivalent strain of about 0.08 is most likely accommodated by the second pyramidal $\langle\mathrm{c}+\mathrm{a}\rangle$ slip. Once slip and/or twinning cannot accommodate the shape change, a sudden loss of strength occurred due to the development of an inhomogeneous deformation in terms of shear bands that leads to softening and eventually cracking.

It is interesting to note that the flow responses and strainhardening rates in $\mathrm{ND}_{0} \mathrm{ED}_{0}$ and $\mathrm{CA} 0 \mathrm{ED}_{0}$ samples are quite 

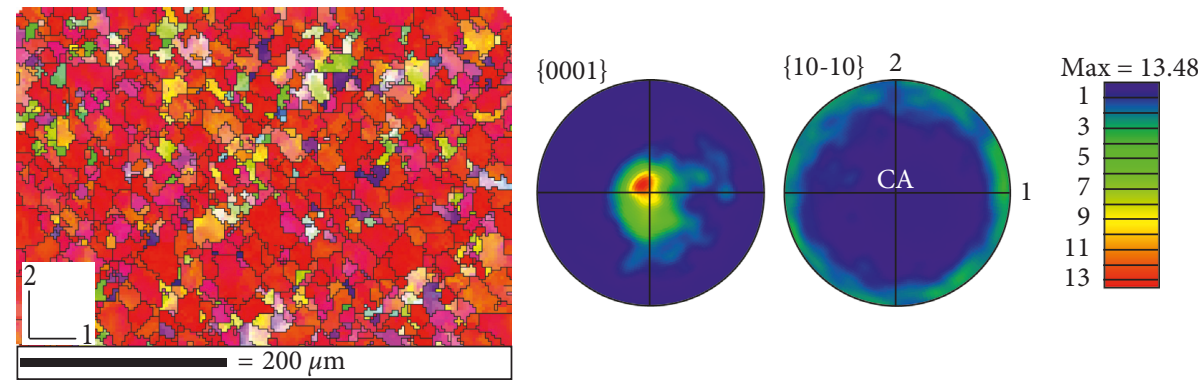

(a)
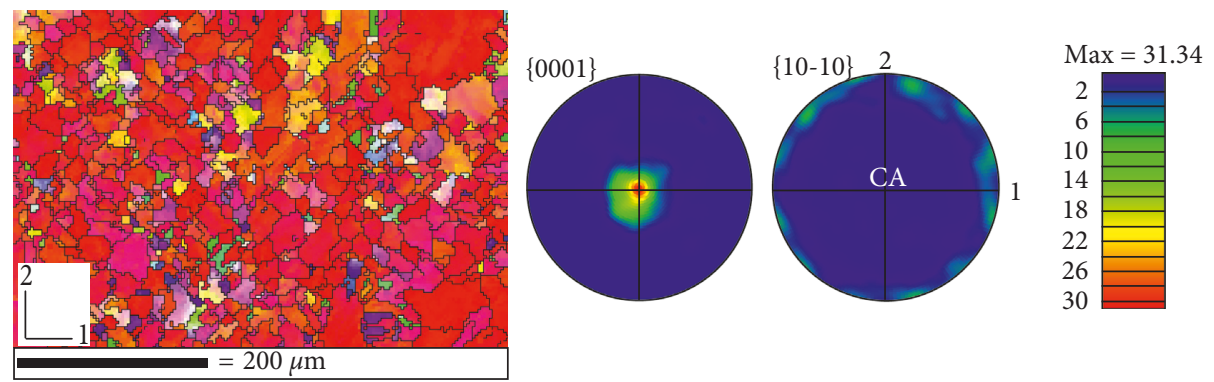

(b)
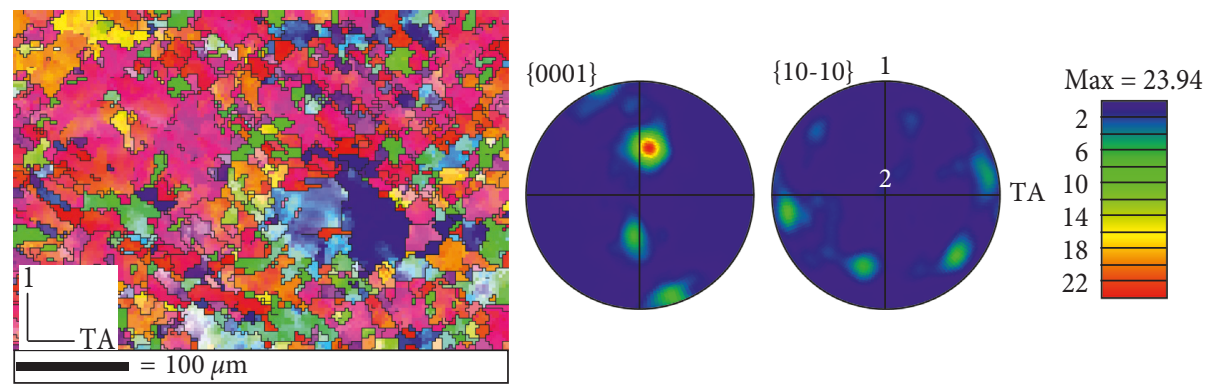

(c)

Figure 7: EBSD inverse pole figure (IPF) maps (left) and pole figures (right) showing texture of (a) $\mathrm{CAOED}_{0}$ and (b) CA0ND $\mathrm{C}_{0}$ pure magnesium samples after simple compression collected in a plane normal to the compression axis CA. The IPF and pole figures in (c) illustrate the texture of $r$ sample after uniaxial tensile test collected in the tensile plane. The labels 1 and 2 in (c) represent the lateral directions of the tension test. The color legend is the same as in Figure 4.

similar in spite of the difference in the applied boundary conditions for the two mechanical tests. To explain this, let us first consider the geometrical constraints in the two mechanical tests. In simple compression with CA normal to the $c$-axis, the sample has no lateral constraint that would suppress the extension of crystals along the $c$-axis as a result of extension twins. However, in plane strain compression with ND normal to the $c$-axis, the crystals with $c$-axis parallel to TD are not expected to twin because twinning would cause broadening in the constrained direction, TD. Thus, only the crystals with $c$-axis not perfectly aligned with TD can twin (especially those with $c$-axis parallel to the free direction, $\mathrm{RD})$. In other words, the amount of twin activities is expected to be higher in simple compression compared to plane strain compression when the loading direction aligns perpendicular to the $c$-axis. This observation has been numerically investigated using crystal plasticity models for ideal orientations in prior literature (e.g. [20, 30, 32]). However, in the current study, it is noted that the flow responses and strain-hardening rates of the plane strain compressed sample $\left.\left(\mathrm{ND}_{\mathrm{ED}}\right)_{0}\right)$ are quite similar to the simple compressed sample $\left(\mathrm{CA} 0 \mathrm{ED}_{0}\right)$. This can be attributed to the existence of many grains in $\mathrm{ND}_{0} \mathrm{ED}_{0}$ sample with enough scatter of the $c$-axis about TD and therefore the easy activation of extension twins compared to other slip systems. This is clearly evidenced by the fact that the final texture of $\mathrm{NDOED}_{0}$ sample at the end of the mechanical test had a strong basal texture and was also supported by the rapid activation of extension twins as predicted by crystal plasticity simulations. It is worth mentioning that the extension twins in magnesium usually grow quickly and encompass the entire grains. Thus, no evidence of a high volume fraction of extension twins was observed in the final microstructure of $\mathrm{ND} \mathrm{ED} \mathrm{D}_{0}$ and $\mathrm{CAOED}_{0}$ samples at the end of the mechanical test.

The samples in the second group $\left(\mathrm{ND}_{0} 0 \mathrm{ED}_{0}, \mathrm{CA0ND}\right.$, and $\mathrm{TA} 90 \mathrm{ND}_{0}$ ) have similar flow stress with falling strainhardening rates as shown in Figure 2. Unlike the samples in the first group, the extension twins are not expected to occur 
in these samples $[10,13,14,33]$. For $\mathrm{ND} 90 \mathrm{ED}_{0}$ and CA0ND samples, the compression direction aligns parallel to the crystallographic $c$-axis in most grains (Figures 5(a) and 5(d)), and therefore the $<\mathrm{a}>$ slips in basal or prismatic slip systems would not be activated. In this case, the second hard pyramidal $\langle\mathrm{c}+\mathrm{a}\rangle$ system is the dominant slip mode that can accommodate the plastic strain. Hence, it is not surprising to see high strain-hardening rates in the early portion of the stress-strain curves. The activation of compression twins is an additional possible deformation mechanism reported in the literature for such deformation modes [11, 20, 21]. For TA90ND $\mathrm{Nample}_{0}$ in the second group, since the tensile axis TA is parallel to the basal plane of most grains (Figure 5(e)), the prismatic $<\mathrm{a}>$ and second pyramidal $<\mathrm{c}+\mathrm{a}>$ slips have more favorable orientations compared to extension twin and basal slip [34, 35].

It is known that the activation of extension twins in magnesium has significant effects on the texture evolution since tensile twins reorient the crystal by $86^{\circ}$ around $1 \overline{2} 10$ directions. This can be clearly seen in the texture evolution of the samples in the first group $\left(\mathrm{NDOED}_{0}\right.$ and $\left.\mathrm{CA0ED} \mathrm{ED}_{0}\right)$. These samples begin the mechanical tests with the loading direction aligned nearly perpendicular to the crystallographic $c$-axis in most grains (Figures $5(b)$ and $5(c)$ ). However, the activation of tensile twins after about 0.03 axial strains alters the orientations of the crystallographic $c$-axis in these samples to become nearly parallel to the loading direction forming the strong basal texture (\{0001\}fiber texture) shown in Figures 6(a) and 7(a). On the other hand, the texture of $\mathrm{ND} 90 \mathrm{ED}_{0}$ and $\mathrm{CA0ND}$ samples in the second group with no active tensile twins did not change significantly (Figures 6(b) and 7(b)) compared to their initial basal texture shown in Figures 5(a) and 5(d). These samples were expected to deform mainly by slip in the second pyramidal $<\mathrm{c}+\mathrm{a}>$ system. It is interesting to note that even though the initial texture of the samples in the two groups before the mechanical tests is different (the loading direction is perpendicular to the $c$-axis in $\mathrm{ND}^{-} \mathrm{ED}_{0}$ and $\mathrm{CA} 0 \mathrm{ED}_{0}$ samples and parallel to the $c$-axis in $\mathrm{ND} 00 \mathrm{ED}_{0}$ and $\mathrm{CA0ND}$ samples), the final texture for these samples is relatively similar. It is also seen that the flow response and strain-hardening rates of the samples in the first group $\left(\mathrm{NDOED}_{0}\right.$ and $\mathrm{CA} 0 \mathrm{ED}_{0}$ ) beyond a small strain of 0.08 (the point at which extension twins deplete or saturate) are roughly similar to the behavior of the $\mathrm{ND} 0 \mathrm{ED}_{0}$ and CA0ND ${ }_{0}$ samples in the second group. This can be related to the similarity in texture and deformation mechanism, where the texture of the $\mathrm{ND}_{0} \mathrm{ED}_{0}$ and $\mathrm{CAOED}_{0}$ samples at 0.08 strain transforms mainly to a basal texture, which is similar to the initial texture of the $\mathrm{ND} 0 \mathrm{ED}_{0}$ and CA0ND . The samples with such a fiber texture deform essentially by slip in the second pyramidal $<\mathrm{c}+\mathrm{a}\rangle$ system.

4.2. Crystal Plasticity Simulation. In order to examine the effect of texture on the activation of various slip and twin systems, the different experimental deformation modes tested in this study were modeled using crystal plasticity constitutive equations. In this model, the plastic velocity
TABLE 1: Various slip and twin systems used in the crystal plasticity simulations for $\mathrm{Mg}$.

\begin{tabular}{|c|c|c|c|c|c|c|c|c|}
\hline \multirow{4}{*}{$\begin{array}{l}\text { System } \\
\text { Basal <a> slip }\end{array}$} & \multicolumn{4}{|c|}{$\begin{array}{c}\text { Shear } \\
\text { direction, } m_{0}\end{array}$} & \multicolumn{4}{|c|}{$\begin{array}{c}\text { Plane } \\
\text { normal, } n_{0} \\
\end{array}$} \\
\hline & 0 & 0 & 0 & 1 & -2 & 1 & 1 & 0 \\
\hline & 0 & 0 & 0 & 1 & 1 & -2 & 1 & 0 \\
\hline & 0 & 0 & 0 & 1 & 1 & 1 & -2 & \\
\hline \multirow{3}{*}{ Prism $<$ a $>$ slip } & 0 & 1 & -1 & 0 & -2 & 1 & 1 & 0 \\
\hline & 1 & 0 & -1 & 0 & 1 & -2 & 1 & 0 \\
\hline & 1 & -1 & 0 & 0 & 1 & 1 & -2 & 0 \\
\hline \multirow{6}{*}{ Pyramidal $<a>$ slip } & 0 & 1 & -1 & 1 & -2 & 1 & 1 & 0 \\
\hline & 0 & -1 & 1 & 1 & -2 & 1 & 1 & \\
\hline & 1 & 0 & -1 & 1 & 1 & -2 & 1 & 0 \\
\hline & -1 & 0 & 1 & 1 & 1 & -2 & 1 & 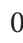 \\
\hline & 1 & -1 & 0 & 1 & 1 & 1 & -2 & \\
\hline & -1 & 1 & 0 & 1 & 1 & 1 & -2 & \\
\hline \multirow{6}{*}{$\begin{array}{l}\text { Second pyramidal } \\
<\mathrm{c}+\mathrm{a}>\text { slip }\end{array}$} & 1 & 1 & -2 & 2 & -1 & -1 & 2 & \\
\hline & -1 & 2 & -1 & 2 & 1 & -2 & 1 & \\
\hline & -2 & 1 & 1 & 2 & 2 & -1 & -1 & 3 \\
\hline & -1 & -1 & 2 & 2 & 1 & 1 & -2 & 3 \\
\hline & 1 & -2 & 1 & 2 & -1 & 2 & -1 & \\
\hline & 2 & -1 & -1 & 2 & -2 & 1 & 1 & 3 \\
\hline \multirow{6}{*}{ Extension twin } & 0 & -1 & 1 & 2 & 0 & 1 & -1 & 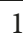 \\
\hline & 1 & 0 & -1 & 2 & -1 & 0 & 1 & 1 \\
\hline & -1 & 1 & 0 & 2 & 1 & -1 & 0 & 1 \\
\hline & 0 & 1 & -1 & 2 & 0 & -1 & 1 & I \\
\hline & -1 & 0 & 1 & 2 & 1 & 0 & -1 & 1 \\
\hline & 1 & -1 & 0 & 2 & -1 & 1 & 0 & 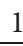 \\
\hline
\end{tabular}

gradient tensor is assumed to have contributions from both slip and deformation twinning $[36,37]$ :

$$
L^{P}=\sum_{\alpha}^{N^{s}} \dot{\gamma}^{\alpha}\left(m_{0}^{\alpha} \otimes n_{0}^{\alpha}\right)+\sum_{\beta}^{N^{\mathrm{tw}}} \dot{f}^{\beta} \gamma^{\mathrm{tw}}\left(m_{0}^{\beta} \otimes n_{0}^{\beta}\right),
$$

where $\dot{\gamma}^{\alpha}$ represents the shearing rate on the slip system $\alpha$, $\gamma^{\text {tw }}$ describes the constant shear associated with the twin system, and $f^{\beta}$ denotes its volume fraction in the given crystal. $m_{0}^{\alpha(\beta)}$ and $n_{0}^{\alpha(\beta)}$ denote the slip (twin shear) direction and the slip (twin) plane normal to the slip (twin) system $\alpha(\beta)$, respectively, in the initial configuration. $N^{s}$ and $N^{\text {tw }}$ refer to the total number of available slip and twin systems, respectively. The evolution of the plastic shearing rate $\dot{\gamma}^{\alpha}$ and the deformation twin volume fraction $\dot{f}^{\beta}$ are quantified using power-law relations $[38,39]$ :

$$
\begin{gathered}
\dot{\gamma}^{\alpha}=\dot{\gamma}_{0}\left|\frac{\tau^{\alpha}}{s_{s}^{\alpha}}\right|^{1 / m} \operatorname{sign}\left(\tau^{\alpha}\right), \\
\dot{f}^{\beta}=\frac{\dot{\gamma}_{0}}{\gamma^{\mathrm{tw}}}\left(\frac{\tau^{\beta}}{s_{\mathrm{tw}}^{\beta}}\right)^{1 / \mathrm{m}},
\end{gathered}
$$

where $\dot{\gamma}_{0}$ is a reference value of slip rate taken as $0.001 \mathrm{~s}^{-1}$ and $m$ is a rate-sensitivity parameter taken as 0.02 and assumed to be the same for both slip and twinning. $\tau^{\alpha} \cdot\left(\tau^{\beta}\right)$ and $s_{s}^{\alpha} \cdot\left(s_{\mathrm{tw}}^{\beta}\right)$ denote the resolved shear stress and slip (twin) resistance of the $\alpha$-slip ( $\beta$-twin) system, respectively. An extended version of the saturation-type hardening laws has been employed in this work to describe the slip-hardening evolution [36-38]: 


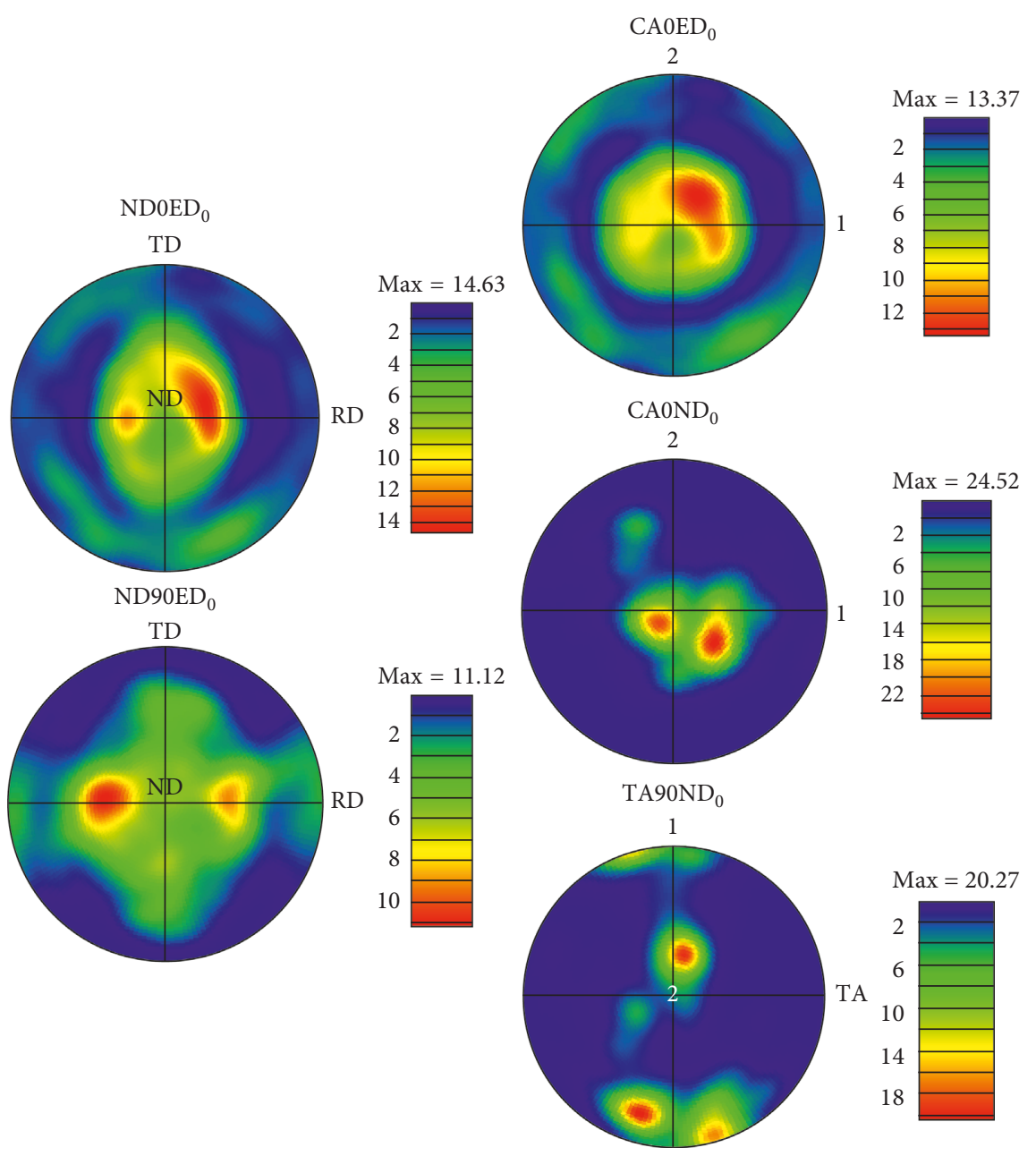

Figure 8: Predicted final texture ( $\{0001\}$ pole figures) using crystal plasticity simulations under the five set of mechanical tests performed in this study: plane strain compression $\left(\mathrm{ND} 0 \mathrm{ED}_{0}\right.$ and $\left.\mathrm{ND} 90 \mathrm{ED}_{0}\right)$, simple compression $\left(\mathrm{CA}_{0 \mathrm{ED}}\right.$ and $\left.\mathrm{CA}_{0} \mathrm{ND}_{0}\right)$, and uniaxial tension $\left(\mathrm{TA} 90 \mathrm{ND}_{0}\right)$.

$$
\begin{aligned}
& \dot{S}_{s}^{\alpha}=h_{s}\left(1+C \sum_{\beta}^{N^{\mathrm{tw}}} f^{\beta}\right)\left(1-\frac{s_{s}^{\alpha}}{s_{\text {sat }}^{\alpha}}\right)^{a} \sum_{k}^{N^{s}} \dot{\gamma}^{k}, \\
& s_{\text {sat }}^{\alpha}=s_{s 0}+s_{\mathrm{pr}}\left(\sum_{\beta}^{N^{\mathrm{tw}}} f^{\beta}\right)^{0.5},
\end{aligned}
$$

where the parameters $h_{s}, C, s_{\text {sat }}^{\alpha}, a$, and $s_{\text {pr }}$ aim to capture the phenomenological slip-hardening behavior due to slip and twin interactions. More details about the physical interpretations of these parameters can be found in [36-38]. The twin resistance was assumed to be constant in the current simulation.

A total of 18 slip systems ( 3 basal $<a>, 3$ prism $<a>, 6$ pyramidal $<\mathrm{a}>$, and $6\{10 \overline{2} 2\}$ second pyramidal $\langle\mathrm{c}+\mathrm{a}\rangle)$ and $6\{10 \overline{1} 2\} \overline{1} 011$ tensile twin systems were considered as listed in Table 1. The simulations were conducted assuming that the slip resistance values for the basal, prismatic, pyramidal $<a>$, second pyramidal $\langle\mathrm{c}+\mathrm{a}\rangle$, and tensile twin modes were in the ratio of $1: 50: 50: 80: 7[30,40,41]$. The values of the various slip and twin hardening parameters in (4) were

established by fitting the measured stress-strain curves of $\mathrm{CA} 0 \mathrm{ND}_{0}, \mathrm{CA} 0 \mathrm{ED}_{0}$, and $\mathrm{TA} 90 \mathrm{ND}_{0}$ samples. These mechanical tests were selected because they produced the most distinct mechanical behavior (Figure 2) since the loading directions align either parallel or perpendicular to the crystallographic $c$-axis in most grains in these samples. The initial texture in the samples was captured using a set of 1000 discrete crystal orientations selected randomly from the initial measured texture. Five loading conditions were simulated corresponding to plane strain compression, simple compression, and uniaxial tensile tests with the loading direction aligned either along the crystallographic $c$-axis or along a direction normal to the $c$-axis. These loading conditions cover the five sets of experiments performed in this study: namely, $\mathrm{ND} 90 \mathrm{ED}_{0}$ (ND $\| c$-axis), $\mathrm{ND}_{0 \mathrm{ED}}\left(\mathrm{ND} \perp c\right.$-axis), $\mathrm{CAOND}_{0}(\mathrm{CA} \| c$-axis), CA0ED (CA $\perp c$-axis), and TA90ND 0 (TA $\perp c$-axis). Figure 8 shows the predicted final textures after an effective strain of about 0.15 for the five set of mechanical tests performed in this study using Taylor-type crystal plasticity simulations. It can be seen that the predicted textures are in reasonable agreement with the measured-final textures shown in Figures 6 and 7. The deviation between the simulated and 


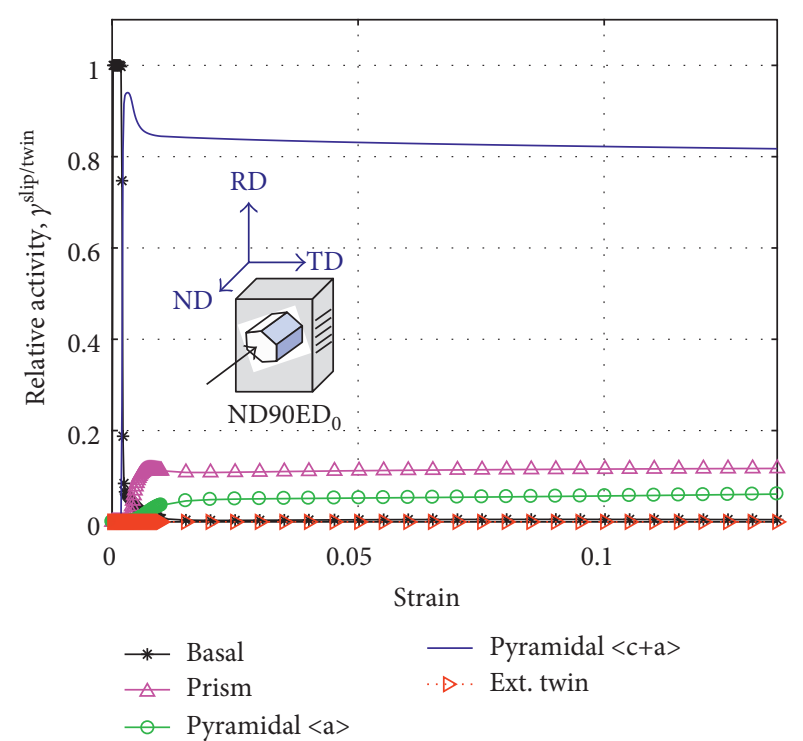

(a)

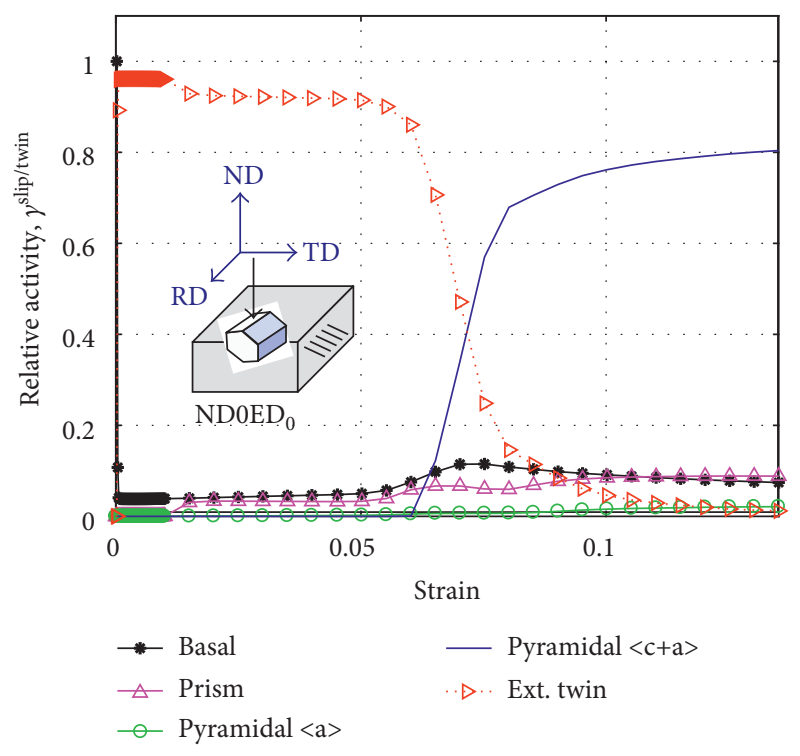

(b)

FIGURE 9: Relative slip and twin activities predicted by crystal plasticity simulation during plane strain compression of pure $\mathrm{Mg}$ for the two sample orientations tested in this study: (a) $\mathrm{ND} 0 \mathrm{ED}_{0}$ sample (ND $\| c$-axis) and (b) $\mathrm{ND}^{2} \mathrm{ED}_{0}$ sample (ND $\perp c$-axis).

measured textures appears in the pole figure of the plane strain compressed samples where the simulated results do not produce the strong-basal texture obtained in the measured texture (Figure 6).

Our main interest is to capture the most favored (active) slip or twin modes for the various loading conditions performed in this study using crystal plasticity simulation. Figure 9 shows the relative slip and twin activities for plane strain compression of pure $\mathrm{Mg}$ with the loading direction aligned either parallel (ND90ED sample) or perpendicular $\left(\mathrm{ND}_{0} \mathrm{ED}_{0}\right.$ sample) to the crystallographic $c$-axis in most grains. The predictions from the crystal plasticity model suggest that much

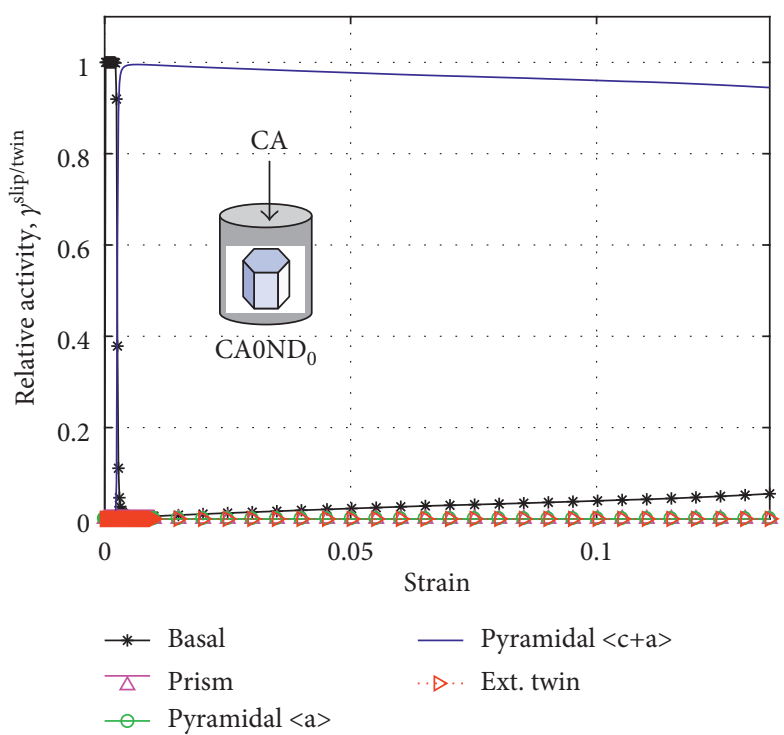

(a)

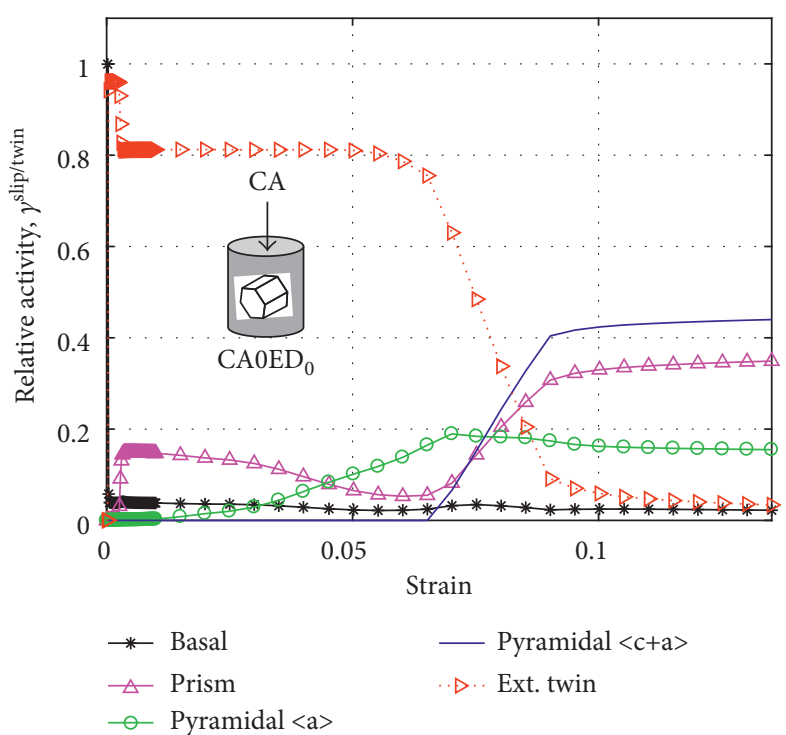

(b)

Figure 10: Relative slip and twin activities predicted by crystal plasticity simulation during simple compression of pure $\mathrm{Mg}$ for the two sample orientations tested in this study: (a) $\mathrm{CAOND}_{0}$ (CA \| $c$-axis) and (b) $\mathrm{CA}_{0} \mathrm{ED}_{0}(\mathrm{CA} \perp c$-axis).

of the plastic strain in $\mathrm{ND} 90 \mathrm{ED}_{0}$ sample (ND $\| c$-axis) is accommodated by the second pyramidal $<\mathrm{c}+\mathrm{a}>$ slip. However, the plastic strain in $\mathrm{ND}_{0} \mathrm{ED}_{0}$ sample (ND $\perp c$-axis) is initially accommodated by the activation of tensile twins up to a strain of about 0.07 , a point at which most grains are oriented such that the $c$-axis becomes nearly parallel to the loading, beyond that the second hard pyramidal $\langle\mathrm{c}+\mathrm{a}\rangle$ slip is activated to accommodate the further deformation. In the case of simple compression, Figure 10 presents the most favored deformation mechanisms predicted by the crystal plasticity simulation. These results are somehow similar to PSC for the two sample orientations tested experimentally in this study: namely, 


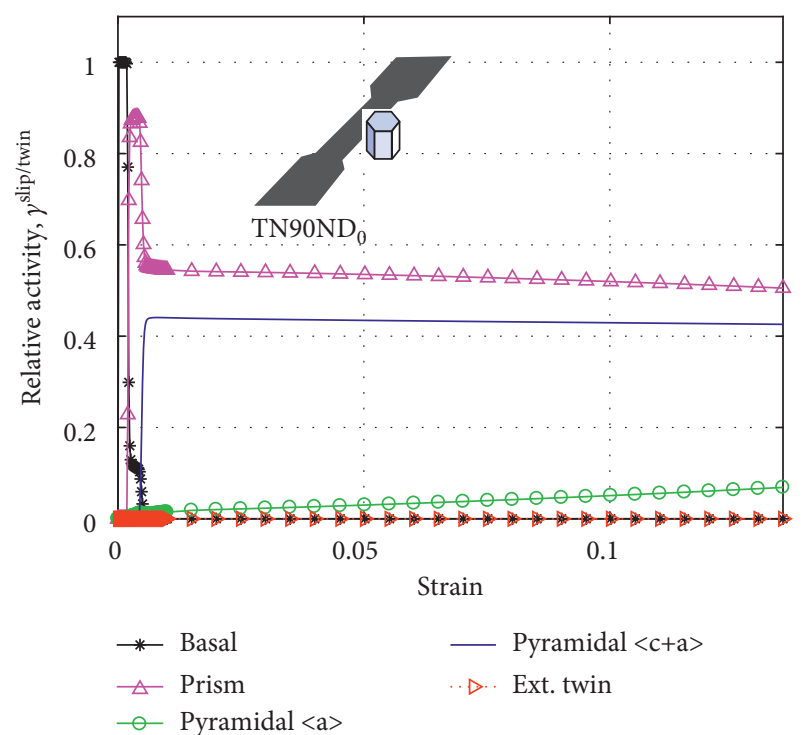

FIGURE 11: Relative slip and twin activities predicted by crystal plasticity simulation during uniaxial tension of pure $\mathrm{Mg}$ with the basal plane parallel to the tensile axis, $\mathrm{TA} 90 \mathrm{ND}_{0}$ sample.

$\mathrm{CA} \mathrm{ND}_{0}\left(\mathrm{CA} \| c\right.$-axis) and $\mathrm{CA} 0 \mathrm{ED}_{0}(\mathrm{CA} \perp c$-axis). More specifically, Figure 10(a) shows that the second pyramidal $<\mathrm{c}+\mathrm{a}\rangle$ slip is the predominant active deformation mechanism in $\mathrm{CAOND}_{0}$ sample (CA $\| c$-axis) for the entire deformation. However, for $\mathrm{CA}_{0} \mathrm{ED}_{0}$ sample (Figure 10(b)), it is seen once again that the tensile twins are initially operated and then followed by the activation of the second pyramidal $<\mathrm{c}+\mathrm{a}\rangle$ slip (after a strain of about 0.07 ). Finally, for the uniaxial tensile test $\left(\mathrm{TA} 90 \mathrm{ND}_{0}\right.$ sample), the crystal plasticity predictions shown in Figure 11 suggest that the plastic strain is most likely accommodated by the prismatic $<\mathrm{a}>$ and second pyramidal $<\mathrm{c}+\mathrm{a}>$ slips. These results are expected for uniaxial tension when the basal plane is parallel to the tensile axis $[34,35]$.

\section{Conclusions}

The anisotropic stress-strain responses of strongly textured pure magnesium were investigated at room temperature under three different monotonic deformation paths: (1) plane strain compression; (2) simple compression; and (3) uniaxial tensile tests. The samples in these mechanical tests were oriented such that the loading direction aligned either parallel or normal to the crystallographic $c$-axis in most of the grains. The main conclusions of this study are summarized below based on our experimental observations and supported by the predicted relative slip and twin activities using crystal plasticity simulations:

(a) The activation of $\{10 \overline{1} 2\}$ tensile twins and the accompanying texture-hardening effect were associated with the initial increase in strain-hardening rate observed in samples subjected to plane strain compression or simple compression with the loading direction normal to the crystallographic $c$-axis. (b) The transition in the stress-strain response from the initial increase in strain-hardening rates to the falling hardening rates was correlated with the exhaustion of deformation twins and the activation of slips along the second pyramidal $<\mathrm{c}+\mathrm{a}>$ systems.

(c) The slip on the second hard pyramidal $<\mathrm{c}+\mathrm{a}>$ system was found to be the dominant deformation mechanism that can accommodate the plastic strains in samples subjected to plane strain compression or simple compression with the loading direction parallel to the crystallographic $c$-axis.

(d) The prismatic $<\mathrm{a}>$ and second pyramidal $<\mathrm{c}+\mathrm{a}>$ slips are the main deformation mechanisms during uniaxial tension when the basal plane is parallel to the tensile axis.

\section{Conflicts of Interest}

The authors declare that they have no conflicts of interest.

\section{Acknowledgments}

The authors extend their appreciation to the Deanship of Scientific Research at King Saud University for funding this work through RAED Project no. NFG-15-03-11.

\section{References}

[1] C. Bettles and M. Gibson, "Current wrought magnesium alloys: strengths and weaknesses," JOM, vol. 57, no. 5, pp. 46-49, 2005.

[2] M. K. Kulekci, "Magnesium and its alloys applications in automotive industry," International Journal of Advanced Manufacturing Technology, vol. 39, no. 9-10, pp. 851-865, 2008.

[3] W. F. Hosford, The Mechanics of Crystals and Textured Polycrystals, Oxford University Press, New York, UK, 1993.

[4] W. F. Hosford and R. M. Caddell, Metal Forming: Mechanics and Metallurgy, Cambridge University Press, Cambridge, UK, 2011.

[5] T. Obara, H. Yoshinga, and S. Morozumi, " $\{11 \overline{2} 2\}\langle 1123\rangle$ slip system in magnesium," Acta Metallurgica, vol. 21, no. 7, pp. 845-853, 1973.

[6] S. R. Agnew, "2-deformation mechanisms of magnesium alloys," Advances in Wrought Magnesium Alloys, pp. 63-104, Woodhead Publishing, Sawston, UK, 2012.

[7] S. Sandlöbes, M. Friák, J. Neugebauer, and D. Raabe, "Basal and non-basal dislocation slip in Mg-Y," Materials Science and Engineering: A, vol. 576, pp. 61-68, 2013.

[8] B. A. Bilby and A. G. Crocker, "The theory of the crystallography of deformation twinning," Proceedings of the Royal Society of London. Series A, Mathematical and Physical Sciences, vol. 288, no. 1413, pp. 240-255, 1965.

[9] J. W. Christian and S. Mahajan, "Deformation twinning," Progress in Materials Science, vol. 39, no. 1-2, pp. 1-157, 1995.

[10] M. R. Barnett, "Twinning and the ductility of magnesium alloys: part I: "tension" twins," Materials Science and Engineering: A, vol. 464, no. 1-2, pp. 1-7, 2007.

[11] M. R. Barnett, "Twinning and the ductility of magnesium alloys: part II. "contraction" twins," Materials Science and Engineering: A, vol. 464, no. 1-2, pp. 8-16, 2007. 
[12] E. Kelley and W. Hosford, "Plane strain compression of magnesium and magnesium alloy crystals," Transactions of the Metallurgical Society of AIME, vol. 24, p. 5, 1968.

[13] R. Gehrmann, M. M. Frommert, and G. Gottstein, "Texture effects on plastic deformation of magnesium," Materials Science and Engineering: A, vol. 395, no. 1-2, pp. 338-349, 2005.

[14] M. D. Nave and M. R. Barnett, "Microstructures and textures of pure magnesium deformed in plane-strain compression," Scripta Materialia, vol. 51, no. 9, pp. 881-885, 2004.

[15] G. T. Gray, "Influence of strain rate and temperature on the structure. Property behavior of high-purity titanium," Le Journal de Physique IV, vol. 7, pp. C3-423-C3-428, 1997.

[16] M. R. Barnett, Z. Keshavarz, A. G. Beer, and D. Atwell, "Influence of grain size on the compressive deformation of wrought Mg-3Al-1Zn," Acta Materialia, vol. 52, no. 17, pp. 5093-5103, 2004.

[17] E. El-Danaf, S. R. Kalidindi, and R. D. Doherty, "Influence of grain size and stacking-fault energy on deformation twinning in fcc metals," Metallurgical and Materials Transactions A, vol. 30, no. 5, pp. 1223-1233, 1999.

[18] A. A. Salem, S. R. Kalidindi, and R. D. Doherty, "Strain hardening of titanium: role of deformation twinning," Acta Materialia, vol. 51, no. 14, pp. 4225-4237, 2003.

[19] R. Hill, The Mathematical Theory of Plasticity, Oxford University Press, Oxford, UK, 1998.

[20] T. Al-Samman and G. Gottstein, "Room temperature formability of a magnesium AZ31 alloy: examining the role of texture on the deformation mechanisms," Materials Science and Engineering: A, vol. 488, no. 1-2, pp. 406-414, 2008.

[21] M. Knezevic, A. Levinson, R. Harris, R. K. Mishra, R. D. Doherty, and S. R. Kalidindi, "Deformation twinning in AZ31: influence on strain hardening and texture evolution," Acta Materialia, vol. 58, no. 19, pp. 6230-6242, 2010.

[22] S. Biswas, S. Suwas, R. Sikand, and A. K. Gupta, "Analysis of texture evolution in pure magnesium and the magnesium alloy AM30 during rod and tube extrusion," Materials Science and Engineering: A, vol. 528, pp. 3722-3729, 2011.

[23] J. Bohlen, S. B. Yi, J. Swiostek, D. Letzig, H. G. Brokmeier, and K. U. Kainer, "Microstructure and texture development during hydrostatic extrusion of magnesium alloy AZ31," Scripta Materialia, vol. 53, no. 2, pp. 259-264, 2005.

[24] N. Dixit, K. Y. Xie, K. J. Hemker, and K. T. Ramesh, "Microstructural evolution of pure magnesium under high strain rate loading," Acta Materialia, vol. 87, pp. 56-67, 2015.

[25] S. Kleiner and P. J. Uggowitzer, "Mechanical anisotropy of extruded Mg-6\% Al-1\% Zn alloy," Materials Science and Engineering: A, vol. 379, no. 1-2, pp. 258-263, 2004.

[26] S. J. Liang, Z. Y. Liu, and E. D. Wang, "Microstructure and mechanical properties of $\mathrm{Mg}-\mathrm{Al}-\mathrm{Zn}$ alloy deformed by cold extrusion," Materials Letters, vol. 62, pp. 3051-3054, 2008.

[27] J. Victoria-Hernandez, S. Yi, D. Letzig, D. Hernandez-Silva, and J. Bohlen, "Microstructure and texture development in hydrostatically extruded $\mathrm{Mg}-\mathrm{Al}-\mathrm{Zn}$ alloys during tensile testing at intermediate temperatures," Acta Materialia, vol. 61, no. 6, pp. 2179-2193, 2013.

[28] J. A. del Valle, F. Carreño, and O. A. Ruano, "Influence of texture and grain size on work hardening and ductility in magnesium-based alloys processed by ECAP and rolling," Acta Materialia, vol. 54, no. 16, pp. 4247-4259, 2006.

[29] S. Suwas, G. Gottstein, and R. Kumar, "Evolution of crystallographic texture during equal channel angular extrusion (ECAE) and its effects on secondary processing of magnesium," Materials Science and Engineering: A, vol. 471, no. 1-2, pp. 1-14, 2007.
[30] J. Zhang and S. P. Joshi, "Phenomenological crystal plasticity modeling and detailed micromechanical investigations of pure magnesium," Journal of the Mechanics and Physics of Solids, vol. 60, no. 5, pp. 945-972, 2012.

[31] G. Zhou, M. K. Jain, P. Wu, Y. Shao, D. Li, and Y. Peng, "Experiment and crystal plasticity analysis on plastic deformation of $\mathrm{AZ} 31 \mathrm{~B} \mathrm{Mg}$ alloy sheet under intermediate temperatures: how deformation mechanisms evolve," International Journal of Plasticity, vol. 79, pp. 19-47, 2016.

[32] Y. Gan, W. Song, and J. Ning, "Crystal plasticity analysis of plane strain deformation behavior and texture evolution for pure magnesium," Computational Materials Science, vol. 123, pp. 232-243, 2016.

[33] X. Y. Lou, M. Li, R. K. Boger, S. R. Agnew, and R. H. Wagoner, "Hardening evolution of AZ31B Mg sheet," International Journal of Plasticity, vol. 23, no. 1, pp. 44-86, 2007.

[34] T. Al-Samman, X. Li, and S. G. Chowdhury, "Orientation dependent slip and twinning during compression and tension of strongly textured magnesium AZ31 alloy," Materials Science and Engineering: A, vol. 527, no. 15, pp. 3450-3463, 2010.

[35] C. J. Geng, B. L. Wu, X. H. Du et al., "Stress-strain response of textured AZ31B magnesium alloy under uniaxial tension at the different strain rates," Materials Science and Engineering: A, vol. 559, pp. 307-313, 2013.

[36] A. A. Salem, S. R. Kalidindi, and S. L. Semiatin, "Strain hardening due to deformation twinning in $\alpha$-titanium: constitutive relations and crystal-plasticity modeling," Acta Materialia, vol. 53, no. 12, pp. 3495-3502, 2005.

[37] X. Wu, S. R. Kalidindi, C. Necker, and A. A. Salem, "Prediction of crystallographic texture evolution and anisotropic stress-strain curves during large plastic strains in high purity $\alpha$-titanium using a Taylor-type crystal plasticity model," Acta Materialia, vol. 55, no. 2, pp. 423-432, 2007.

[38] S. R. Kalidindi, "Incorporation of deformation twinning in crystal plasticity models," Journal of the Mechanics and Physics of Solids, vol. 46, no. 2, pp. 267-290, 1998.

[39] A. Needleman, R. J. Asaro, J. Lemonds, and D. Peirce, "Finite element analysis of crystalline solids," Computer Methods in Applied Mechanics and Engineering, vol. 52, no. 1-3, pp. 689-708, 1985.

[40] Y. Gan, W. Song, J. Ning, H. Tang, and X. Mao, "An elastic-viscoplastic crystal plasticity modeling and strain hardening for plane strain deformation of pure magnesium," Mechanics of Materials, vol. 92, pp. 185-197, 2016.

[41] J. Zhang, Q. Wei, and S. P. Joshi, "Effects of reinforcement morphology on the mechanical behavior of magnesium metal matrix composites based on crystal plasticity modeling," Mechanics of Materials, vol. 95, pp. 1-14, 2016. 


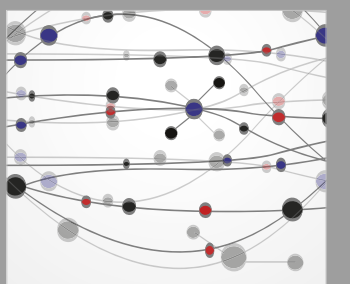

The Scientific World Journal
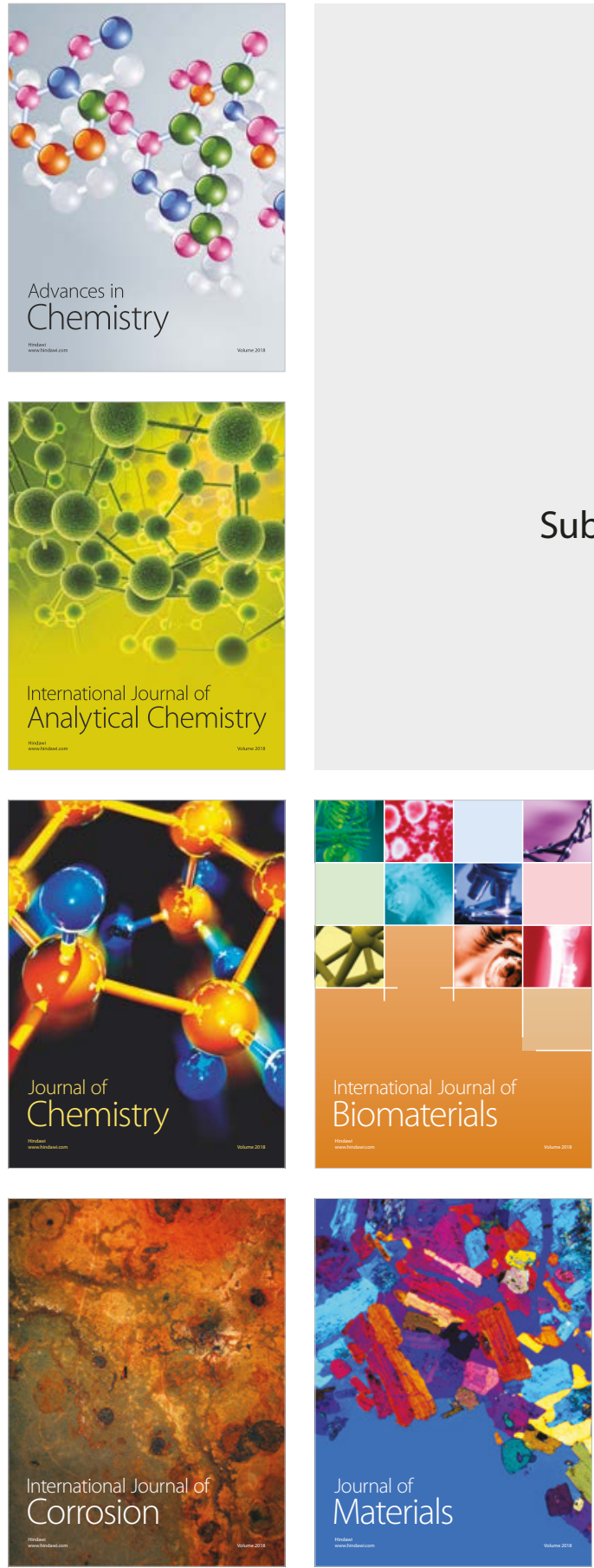

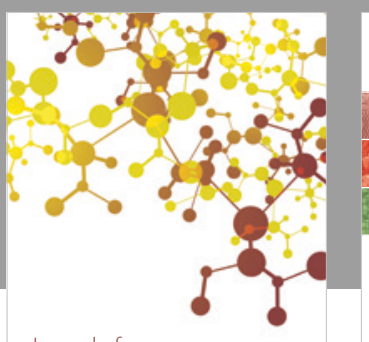

Journal of

Applied Chemistry
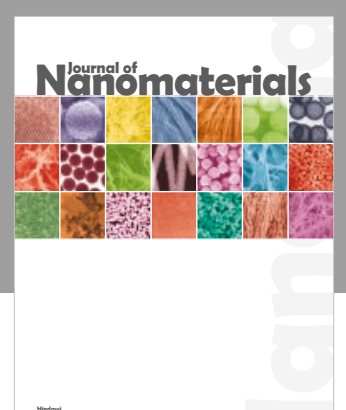

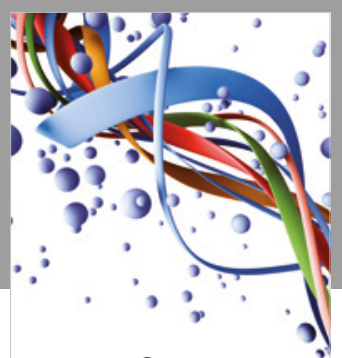

Scientifica

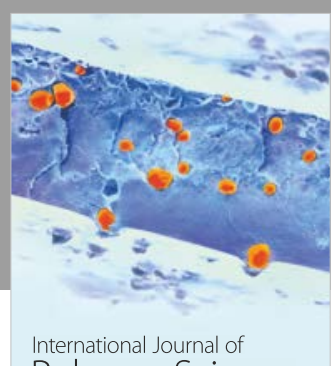

Polymer Science

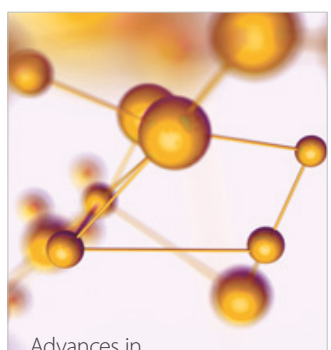

Physical Chemistry
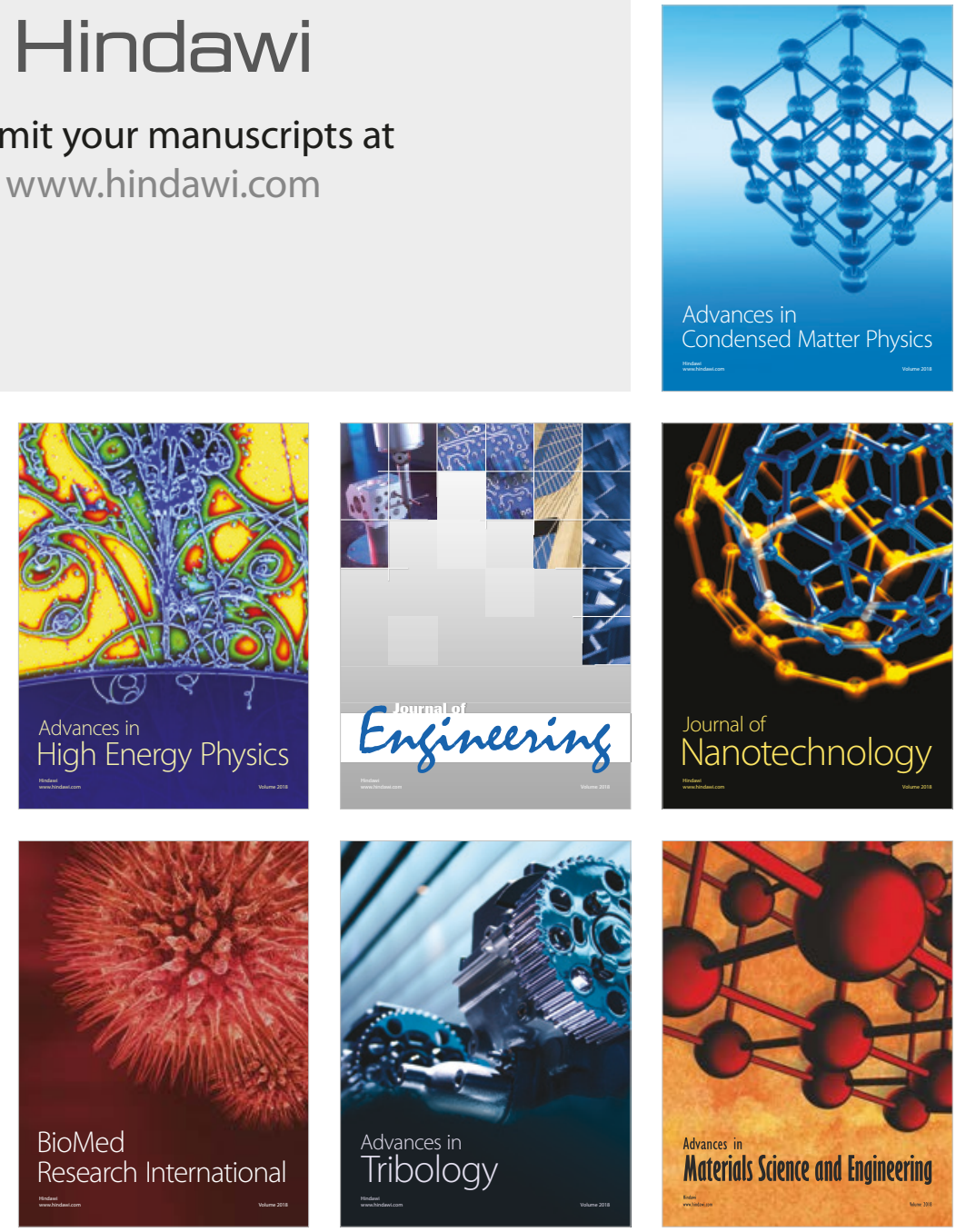